\title{
Rodent-specific hypoxia response elements enhance PAI-1 expression through HIF-1 or HIF-2 in mouse hepatoma cells
}

\author{
YONG-TAE AHN ${ }^{1}$, MEI-SZE CHUA ${ }^{2}$, JAMES P. WHITLOCK $\mathrm{Jr}^{3}$, YONG-CHIL SHIN ${ }^{4}$, \\ WOON-HEUNG SONG ${ }^{4}$, YONGKUK KIM ${ }^{5}$, CHI-YONG EOM ${ }^{6}$ and WON GUN AN ${ }^{7}$
}

\begin{abstract}
Departments of ${ }^{1}$ Pediatrics, ${ }^{2}$ Surgery, ${ }^{3}$ Chemical and Systems Biology, Stanford University School of Medicine, 300 Pasteur Dr. Stanford, CA 94305, USA; ${ }^{4}$ Department of Clinical Laboratory Science, Shin Heung College University, 117 Howon-Dong, Euijungbu, Kyungki-do 480-701; ${ }^{5}$ Laboratory of Mathematical and Computational Biology, Department of Mathematics, Kyungpook National University, Daegu 702-701; ${ }^{6}$ Korea Basic Science Institute, Seoul 136-173; ${ }^{7}$ Joint-Research Center of Pusan National University-Fraunhofer IGB, School of Korean Medicine, Pusan National University, Busan 609-735, Korea
\end{abstract}

Received July 8, 2010; Accepted September 2, 2010

DOI: $10.3892 /$ ijo_00000817

\begin{abstract}
Plasminogen activator inhibitor-1 (PAI-1) is an important regulator of numerous pathophysiological processes such as inflammation, thrombosis, angiogenesis and tumor metastasis. Its expression is induced by hypoxia at the transcriptional level, via the hypoxia inducible factor-1 (HIF-1) or -2 (HIF-2). In this study, we elucidated the mechanism of transcriptional regulation of mouse PAI-1 gene by hypoxia in mouse hepatoma cells. We searched for hypoxia response elements (HREs) of murine PAI-I promoter using several molecular biological assays. DNAse I hypersensitivity assay first suggested that $P A I-1$ gene expression is up-regulated by protein-DNA interactions at the -3.6- and -3-kb upstream regions of the PAI-1 gene transcription start site. An approximately $6.4-\mathrm{kb}$ region of DNA containing the 5'-flanking promoter region of the PAI-1 gene was isolated, mapped, and cloned into reporter gene assay vectors and sequenced. Luciferase reporter gene assay subsequently identified two functional HREs, located around $-3.6 \mathrm{~kb}$ of the 5'-flanking promoter region of PAI- 1 gene that were responsible for the enhancement of luciferase reporter gene activity. Mutation of the HREs in this fragment abolished luciferase reporter gene activity. Finally, in vitro and in vivo protein-DNA interaction assays confirmed binding of the two HREs to HIF-1 or HIF-2 protein. Our results show that two HREs located around $-3.6 \mathrm{~kb}$ of the 5 '-flanking promoter region of the mouse PAI- 1 gene function
\end{abstract}

Correspondence to: Dr Won Gun An, Joint-Research Center of Pusan National University-Fraunhofer IGB, School of Korean Medicine, Pusan National University, Busan 609-735, Korea

E-mail:wgan@pusan.ac.kr

Key words: Plasminogen activator inhibitor-1, hypoxia inducible factor-1, hypoxia inducible factor-2, hypoxia response element, enhancer, transcription, Hepa1c1c7 cells, $\mathrm{BP}^{\mathrm{r}} \mathrm{C} 1$ cells, hypoxia, protein-DNA interaction as hypoxia enhancers, which, alongside other regulatory regions, control PAI-1 gene transcription by HIF-1 or HIF-2 under hypoxic environments in mouse hepatoma cells.

\section{Introduction}

The stringent regulation of gene expression in response to endogenous and exogenous stimuli is fundamental to life. Aberrant gene expression resulting from toxic or otherwise undesirable stimuli may alter the balance of the biological system and lead to human diseases such as ischemia, inflammation and malignancy. The basic helix-loop-helix/Per-AhRArnt-Sim (bHLH/PAS) proteins are an important group of sensing molecules that link the environment to development and physiology by transactivating the expression of many genes (1-3). This group of transcription factors includes the aryl hydrocarbon receptor (AhR) and its dimerization partner AhR nuclear translocator (Arnt) (1), as well as the hypoxia inducible factor- $1 \alpha, 2 \alpha$ and $-3 \alpha(4,5)$. The physiological and pathological responses to hypoxia are mediated by the hypoxiainducible factor-1 or -2 [HIF-1 or HIF-2; a heterodimer of stabilized HIF- $1 \alpha$ or HIF- $2 \alpha$ and Arnt protein (also known as HIF-1ß)] in the nucleus $(5,6)$. This heterodimer complex then binds to the hypoxia response element (HRE; 5'-RCGTG-3', $\mathrm{R}=\mathrm{A}$ or $\mathrm{G}$ ) to activate the transcription of $>100$ downstream target genes (1). Plasminogen activator inhibitor-1 (PAI-1) is a well-known target gene induced by hypoxia (7-12), although the detailed mechanism(s) underlying the induction is not fully understood.

PAI-1 is a specific and potent inhibitor of urokinase type plasminogen (u-PA) and tissue-type plasminogen (t-PA) activators, and is therefore a key regulator of the fibrinolysis process (13). However, its function is not limited to fibrinolysis, since plasmin (the active product of $\mathrm{u}-\mathrm{PA}$ and t-PA catalysis) performs additional functions such as degradation of extracellular matrix and activation of growth factors (including vascular endothelial growth factor required for neovascularization) (14). Through these systems, PAI-1 has the ability to modulate cell adhesion/migration and neovascularization; and expectedly it has been implicated in tumor 
invasion, metastasis and angiogenesis, processes characteristic of high-grade malignancy $(15,16)$. In addition, PAI-1 was shown to inhibit apoptosis and thus promote tumor growth and aggressiveness (17). PAI-1 may partly mediate the antiapoptotic effects of the p53 tumor suppressor and the c-myc oncogene, both of which have been reported to dysregulate the expression of PAI-1 $(18,19)$. High levels of PAI-1 in tumors is consistently predictive of poor prognosis $(20,21)$. Drug-resistant tumor cells appear to express increased levels of tumor markers for invasion and metastasis, including PAI-1 (22). Thus, understanding the regulation of PAI-1 expression by hypoxic stress is relevant to important processes such as coagulation, angiogenesis and tumor metastasis.

To study the mechanisms of PAI-1 regulation by hypoxia, we used mouse hepatoma cells (Hepa1c1c7) and its Arnt $^{-/-}$ cells $\left(\mathrm{BP}{ }^{\mathrm{r}} \mathrm{C} 1\right)$ because they have proven to be a powerful experimental system in our previous studies of glucose transporter 1 (Glut1) and phosphoglycerate kinase 1 (PGK1) gene regulation by hypoxia (23). Herein, we report characterizing the murine-specific enhancer elements on the mouse $P A I-1$ gene to elucidate the mechanism of transcriptional control of $P A I-1$ gene expression by hypoxia in mouse hepatoma cells. Our data provide new insights into the mechanism of PAI-1 expression in response to hypoxic stress, which may have implications for cancer gene therapy.

\section{Materials and methods}

Cell culture. Hepa1c1c7 and $\mathrm{BP}^{\mathrm{r}} \mathrm{C} 1$ were routinely cultured in $\alpha$-minimum essential medium, in a humidified incubator maintained at $37^{\circ} \mathrm{C}$ and $95 \%$ air $/ 5 \% \mathrm{CO}_{2}$.

Northern blot analysis. Cells were grown to $80 \%$ confluency and exposed to hypoxia $\left(2.0 \% \quad \mathrm{O}_{2} / 5 \% \quad \mathrm{CO}_{2} / 93 \% \mathrm{~N}_{2}\right)$ in an automatic $\mathrm{CO}_{2} / \mathrm{O}_{2}$ incubator for $24 \mathrm{~h}$. Un-induced cells were cultured under normoxic conditions $\left(20 \% \mathrm{O}_{2} / 5 \% \mathrm{CO}_{2}\right)$. Total RNA was isolated using the RNeasy kit (Qiagen, Valencia, CA) according to the manufacturer's instructions, quantified spectrophotometrically at $260 \mathrm{~nm}$ and checked for integrity by electrophoresis on a $1 \%$ agarose gel. Equal amounts $(10 \mu \mathrm{g})$ of each sample were electrophoresed on a $1 \%$ agarose formaldehyde gel and capillary transferred (in 10X SSC) onto nylon membranes overnight. RNA was then UV crosslinked onto the nylon membranes. A PAI- 1 cDNA probe (786 bp, 701-1487 of the mouse PAI-1 cDNA sequence from a GenBank accession no. M33961) was labeled with [ $\left.\alpha^{-32} \mathrm{P}\right]-$ dCTP using Rediprime random primer labeling kit (Amersham Pharmacia Biotech Inc., Piscataway, NJ). Hybridization was done at $68^{\circ} \mathrm{C}$ for $18 \mathrm{~h}$ using the Expresshyb Hybridization solution (Clontech, Mountain View, CA). Membranes were washed with $2 \mathrm{X} \mathrm{SSC}, 0.05 \% \mathrm{SDS}$ for $2 \times 20 \mathrm{~min}$ at $55^{\circ} \mathrm{C}$, and with $0.1 \% \mathrm{SSC}, 0.1 \% \mathrm{SDS}$ for $2 \times 20 \mathrm{~min}$ at $65^{\circ} \mathrm{C}$ before exposing to Hyperfilm at $-80^{\circ} \mathrm{C}$. Membranes were stripped of $P A I-1$ cDNA probes and re-probed with actin cDNA to check equality of sample loading.

Western blot analysis. Total cell proteins from un-induced (normoxia) or induced (hypoxia) Hepa1c1c7 as well as $\mathrm{BP}^{\mathrm{r}} \mathrm{C} 1$ cells were separated by SDS-PAGE. The separated proteins were transferred onto PVDF membranes, and the membranes were blocked with 5\% non-fat dry milk in PBS/0.1\% Tween-20 (PBST) for $1 \mathrm{~h}$ at room temperature. Membranes were incubated for $2 \mathrm{~h}$ with anti-PAI-1 or antiactin antibody (Santa Cruz Biotechnology, Santa Cruz, CA), washed three times with PBST, and incubated with HRPconjugated secondary antibody (Amersham Pharmacia Biotech). Membranes were washed five times for 10 min with PBST and then subjected to chemiluminescence by the addition of ECL (Amersham Pharmacia Biotech Inc., Piscataway, NJ), and exposed to film.

Lambda plaque screening for PAI-1 gene. Host strain [E. coli XL1-Blue MRA (P2) strain] was cultured in LB broth supplemented with $0.2 \%$ maltose and $10 \mathrm{mM} \mathrm{MgSO}_{4}$ overnight with shaking at $30^{\circ} \mathrm{C}$. The cells were spun down for $10 \mathrm{~min}$ at $2000 \mathrm{rpm}$ and diluted into OD600 $=0.5$ with $10 \mathrm{mM}$ $\mathrm{MgSO}_{4}$. Mouse lambda DASH II Library (C57 black/6 liver, female, 1 year; Stratagene, La Jolla, CA) containing 5x10 plague forming unit (pfu) of bacteriophage was mixed with $600 \mu 1$ of the diluted host cells. To amplify $1 \times 10^{6}$ plaques, 20 plates $(150 \mathrm{~mm})$ were used. The mixture was incubated for $15 \mathrm{~min}$ at $37^{\circ} \mathrm{C}$, mixed with $6.5 \mathrm{ml}$ of top agarose and spread evenly onto a freshly poured $150-\mathrm{mm}$ bottom agar plate. After $8 \mathrm{~h}$ incubation at $37^{\circ} \mathrm{C}$, the plates were chilled for $2 \mathrm{~h}$ at $4^{\circ} \mathrm{C}$. The plaques were transferred onto nylon membranes for $2 \mathrm{~min}$, denatured in a solution containing $1.5 \mathrm{M} \mathrm{NaCl}$ and $0.5 \mathrm{M} \mathrm{NaOH}$ for $5 \mathrm{~min}$, neutralized in a solution containing $1.5 \mathrm{M} \mathrm{NaCl}$ and $0.5 \mathrm{M}$ Tris- $\mathrm{HCl}, \mathrm{pH} 7.5$ for $5 \mathrm{~min}$, and rinsed in a Tris buffer $(0.2 \mathrm{M}$ Tris- $\mathrm{HCl}, \mathrm{pH} 7.5) / 2 \mathrm{X}$ SSC. Following UV-crosslinking of the DNA to the membrane for $30 \mathrm{sec}$, the membranes were prehybridized for $2 \mathrm{~h}$ at $60^{\circ} \mathrm{C}$, and then hybridized overnight at $60^{\circ} \mathrm{C}$ with same probe used in Northern blotting. The membranes were washed with $2 \mathrm{X}$ $\mathrm{SSC}$ and $0.05 \% \mathrm{SDS}$ for $1 \mathrm{~h}$ at $60^{\circ} \mathrm{C}$ and then with $0.1 \mathrm{X}$ SSC and $0.1 \%$ SDS for $1 \mathrm{~h}$ at $60^{\circ} \mathrm{C}$. The membranes were exposed to $\mathrm{X}$-ray film at $-80^{\circ} \mathrm{C}$. Positive plaques were amplified and their DNAs were purified.

Plasmid constructs. An approximately 55-kb DNA fragment was isolated from lambda DASH II mouse Library and mapped by several restriction enzymes. For luciferase reporter analysis, $6.4 \mathrm{~kb}$ of 5'-flanking region of PAI-1 fragment was copied by PCR and ligated with $5 \mathrm{~kb}$ of pGL3 basic vector (Invitrogen, Carlsbad, CA) and named pGL3-5HS. In addition, pGL3-4HS and pGL3-2HS were constructed from pGL3-5HS by EcoRV digestion at $-6.4 \mathrm{~kb}, \mathrm{Xba \textrm {I }}$ at $-5.4 \mathrm{~kb}$ and $S m a \mathrm{I}$ at $-2.1 \mathrm{~kb}$. The constructs pGL3-EX and pGL3-XS were made from pGL3-5HS by EcoRV digestion at $-6.4 \mathrm{~kb}$, $\mathrm{XbaI}$ at $-5.4 \mathrm{~kb}$ and $S m a \mathrm{I}$ at $-2.1 \mathrm{~kb}$ with the pGL3 promoter vector. The constructs pGL3-HS(-3) and pGL3-HS(-3.6) were made by the ligation of 5 -flanking region of $P A I-1$ fragments -3136 to $-2985 \mathrm{bp}$ and -3900 to $-3547 \mathrm{bp}$, to the pGL3 promoter vector, respectively. Mutants pGL3-HS(-3.6)M1, pGL3-HS(-3.6)M2, pGL3-HS(-3.6)M3, pGL3-HS(-3.6)M4 and pGL3-HS(-3.6)M5 were made from pGL3-HS(-3.6) by PCR using primers designed with mutated HRE. We used the promoter of PGK1-promoter and pGL3 basic vector (pGL3PPGK1) which consists of the HREs of the PGK-1 gene (23) ligated to the pGL3 basic vector as a positive control, and a 
non-functional mutant mPPGK1-pGL3 construct (pGL3mPPGK1) as a negative control. We also used pGL3-5 (HRE), which is made from 5 random repeated HREs linked to the pGL3-promoter vector as a positive control.

Sequencing of 5'-flanking region of PAI-1 gene. By using primers of the pGL3 vector, the 5'-flanking region of the PAI-1 gene (up to about $-7 \mathrm{~kb}$ ) from the above constructs was sequenced and the sequence data were sent to DDBJ (accession no. AB331006).

Transient transfection and luciferase assay. Cells were seeded onto 6-well plates $18 \mathrm{~h}$ before transfection, such that cells were $50-80 \%$ confluent on the day of transfection. To each well, a total of $4 \mu \mathrm{g}$ DNA was transfected: $1 \mu \mathrm{g}$ pcDNA-HIF- $1 \alpha$ or $1 \mu \mathrm{g}$ pcDNA-HIF- $2 \alpha, 0.5 \mu \mathrm{g}$ firefly luciferase reporter plasmid, $0.1 \mu \mathrm{g}$ pRL-TK vector plasmid (expressing Renilla luciferase, as internal standard for transfection efficiency) and $2.4 \mu \mathrm{g}$ pUC19 (to standardize the total amount of transfected DNA). Transfection was done using SuperFect Transfection Reagent (Qiagen, Valencia, CA) according to the manufacturer's protocol. Cells were harvested $24 \mathrm{~h}$ after transfection and luciferase activities measured using Dual luciferase reporter assay system (Promega, Madison, WI) and a Lumat LB 9507 luminometer according to manufacturer's instructions. For studies on hypoxia inducibility, transfected cells were exposed to $2 \% \mathrm{O}_{2}$ for $24 \mathrm{~h}$, then harvested for measurement of reporter gene activities. Firefly luciferasereporter gene activities were normalized to the Renilla luciferase activities. Experiments were done in triplicates.

DNAse I hypersensitivity assay. DNAse I, proteinase K, restriction endonucleases, buffer-saturated phenol and phenol:chloroform:isoamyl alcohol $(25: 24: 1)$ were from Gibco BRL Life Technologies, Inc. (Gaithersburg, MD). Cells were grown to $70 \%$ confluency and treated with $2 \% \mathrm{O}_{2}$ for $4 \mathrm{~h}$. Nuclei were isolated and aliquots (equivalent to $10^{7}$ nuclei) were digested with $0-20 \mathrm{U} / \mathrm{ml}$ of DNAse I for $90 \mathrm{sec}$ at $20^{\circ} \mathrm{C}$, in a total volume of $2 \mathrm{ml}$. Digestion was stopped by addition of $2 \mathrm{ml}$ of stop buffer [ $20 \mathrm{mM}$ Tris- $\mathrm{HCl}(\mathrm{pH} \mathrm{8.0)}$, $20 \mathrm{mM} \mathrm{NaCl}, 20 \mathrm{mM}$ EDTA, $1 \%$ sodium dodecyl sulfate (SDS), $600 \mu \mathrm{g} / \mathrm{ml}$ proteinase $\mathrm{K}$ ], and genomic DNA was purified. Purified genomic DNA was quantified spectrophotometrically at $260 \mathrm{~nm}$ and $20 \mu \mathrm{g}$ of each sample was restriction digested with $X h o I$ or BstEII. Samples were purified by phenol: chloroform extraction and ethanol precipitation, and precipitated DNA pellets resuspended in water for electrophoresis on a $1 \%$ agarose gel. Fractionated DNA was then capillary transferred onto nylon membranes overnight in 10X SSC. Transferred DNA was UV crosslinked onto the nylon membranes and hybridized with a 380-bp probe (BstEII/XhoI restriction fragment) overnight at $60^{\circ} \mathrm{C}$ in the Clontech Expresshyb hybridization solution. Membranes were washed to a final stringency in $0.1 \mathrm{X} \mathrm{SSC}, 0.1 \% \mathrm{SDS}$ at $65^{\circ} \mathrm{C}$ and exposed to Hyperfilm-MP at $-80^{\circ} \mathrm{C}$.

In vivo footprinting and ligation-mediated (LM)-PCR. To demonstrate protein-DNA interactions in situ, dimethyl sulfate (DMS)-piperidine and DNAse I methods (24) were used. In the DMS modification and piperidine cleavage of genomic DNA, cells were removed from normoxic or hypoxic conditions and immediately treated with DMS (5 $\mu 1$ of $\mathrm{DMS} / \mathrm{ml}$ of culture medium) for $90 \mathrm{sec}$ at room temperature. After removing media containing DMS and washing with PBS, $2 \mathrm{ml}$ of stop buffer (20 mM Tris-HCl, pH 8.0, $20 \mathrm{mM}$ $\mathrm{NaCl}, 20 \mathrm{mM}$ EDTA, $1 \% \mathrm{SDS}, 600 \mu \mathrm{g} / \mathrm{ml}$ proteinase K) was added to each plate and the viscous solution was collected into a $15-\mathrm{ml}$ tube containing $2 \mathrm{ml}$ of dilution buffer $(150 \mathrm{mM}$ $\mathrm{NaCl}, 5 \mathrm{mM}$ EDTA), and incubated at $37^{\circ} \mathrm{C}$ for $3 \mathrm{~h}$. The purified DNA was mixed with piperidine solution and incubated at $70^{\circ} \mathrm{C}$ for $90 \mathrm{~min}$, then dry vacuumed to evaporate piperidine. The purified DNA was then analyzed by LMPCR. For DNAse I digestion of genomic DNA, cells under the normoxic or hypoxic conditions were removed from the incubator, and the culture medium of cells was immediately removed and replaced with $3 \mathrm{ml}$ of digestion buffer $(150 \mathrm{mM}$ sucrose, $80 \mathrm{mM} \mathrm{KCl,} 35 \mathrm{mM}$ HEPES, pH 7.4, $5 \mathrm{mM} \mathrm{K}_{2} \mathrm{HPO}_{4}$, $5 \mathrm{mM} \mathrm{MgCl} 2,2 \mathrm{mM} \mathrm{CaCl}{ }_{2}, 0.01 \%$ lysolecithin, $20 \mu \mathrm{g}$ DNAse $\mathrm{I} / \mathrm{ml}$ ) at room temperature for $2.5 \mathrm{~min}$. The digestion buffer was then removed and replaced with $2 \mathrm{ml}$ of stop buffer. The viscous solution was collected into a tube containing $2 \mathrm{ml}$ of dilution buffer, and incubated at $37^{\circ} \mathrm{C}$ for $3 \mathrm{~h}$. The genomic DNA was then purified and analyzed by LM-PCR as described previously (24) with the following primer sets: Set A consists of the following to analyze the sense strand of the $-3.6 \mathrm{~kb}$ of the $P A I-1$ gene: primer 1: 5'-GCAGGGGACA GTCATGGAAAT-3'; primer 2: 5'-GCTCCAATTACACCT GCAGAGGGAC-3'; primer 3: 5'-CACCTGCAGAGGG ACCAGATGGAGCCAT-3'. Set B consists of the following to analyze the antisense strand of the $-3.6-\mathrm{kb}$ region of the PAI-1 gene: primer 1: 5'-CCACTTTGACCTCATCCTCTT-3'; primer 2: 5'-TTGACCCTTTGGTAGGTGGGGGGAG-3'; primer 3: 5'-AGGGGCGGGGATCAAATGGCCAGAATG-3'. Set $\mathrm{C}$ consists of the following to analyze the sense strand of the -200-bp region of the PAI-1 gene: primer 1: 5'-TACTTC CAAGGGTCTAGACGAC-3'; primer 2: 5'-CTAGACGACC GACCAGCCAAAGCAG-3'; primer 3: 5'-CGACCAGCC AAAGCAGCAGGGATGTTCC-3'. Set D consists of the following to analyze the antisense strand of the -200-bp region of the PAI-1 gene: primer 1: 5'-CCAGATGTGAGCCGGA AATAGA-3'; primer 2: 5'-GATGAACTCATGTTCCAGC CCCACC-3'; primer 3: 5'-CCAGCCCCACCCACTTTCT AACTCTGG-3'.

Electrophoretic mobility shift assay (EMSA). EMSA was performed with a gel shift assay. Briefly, complementary oligonucleotide pairs, 5'-TTCCCGGCCCCACGTACCTCA CGCTCTTATCTCTG-3' and 5'-CAGAGATAAGAGCGTG AGGTACGTGGGGCCGGGAA, corresponding to the PAI-1 promoter sequences from -3639 to -3604 were synthesized, hybridized and used as the substrate for this binding reactions. The oligonucleotide pairs were annealed and end-labeled with $\left[\gamma^{-32} \mathrm{P}\right]$-dATP using T4 polynucleotide kinase. The labeled probe was separated from unincorporated nucleotides using G-50 columns (Amersham Pharmacia Biotech, Inc., Piscataway). For the binding reactions, a total volume of $20 \mu 1$ containing $5 \mu \mathrm{g}$ nuclear extract obtained from hypoxia-treated Hepa1c1c7 cells, 30 fmol ${ }^{32} \mathrm{P}$-labeled oligonucleotides, and a non-specific competitor (300 ng poly $\mathrm{dI} / \mathrm{dC}$ ) in a binding buffer with a final concentration of $12 \mathrm{mM}$ HEPES, $4 \mathrm{mM}$ Tris 
A

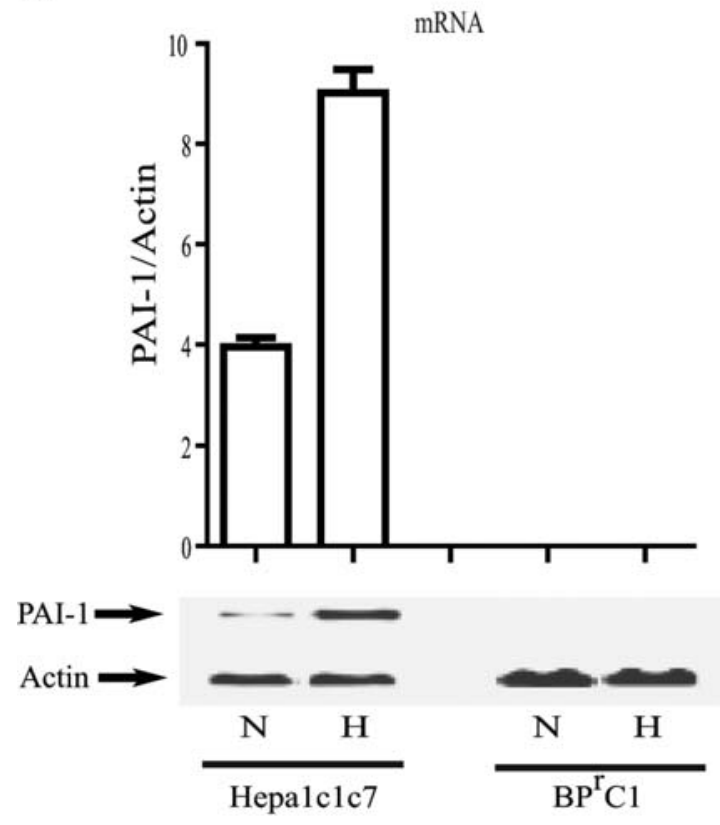

B

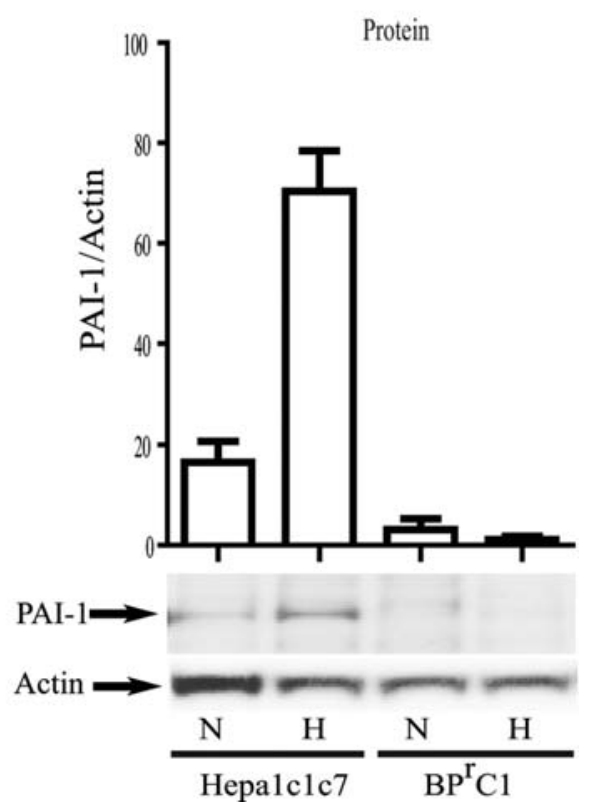

Figure 1. PAI-1 mRNA (A) and protein (B) expression of Hepa1c1c7 (Arnt ${ }^{+/+}$) cells or BPrC1 (Arnt ${ }^{-/}$) cells under normoxia and hypoxia. (A) For Northern blotting of PAI-1 mRNA, equal amounts $(10 \mu \mathrm{g})$ of total RNA from mouse Hepa1c1c7 cells or BP C1 cells were electrophoresed on a $1.2 \%$ agaroseformaldehyde gel and transferred onto membrane, then hybridized with a ${ }^{32} \mathrm{P} P A I-1 \mathrm{cDNA}$ probe. The membrane was stripped and re-probed with ${ }^{32} \mathrm{P}$ actin to normalize for loading. (B) For Western blotting of PAI-1 protein, specific antibody against PAI-1 or actin was used to detect PAI-1 or actin protein, respectively. For both (A) and (B), PAI-1 signal intensities were normalized to that of actin, and the relative abundance of PAI-1 plotted as mean \pm standard deviation of three independent experiments. $\mathrm{N}$, normoxia; $\mathrm{H}$, hypoxia.

(pH 7.9), $60 \mathrm{mM}$ potassium chloride, $1 \mathrm{mM}$ EDTA, and $1 \mathrm{mM}$ dithiothreitol. After incubation for $30 \mathrm{~min}$ at room temperature, $5 \mu \mathrm{g}$ anti-HIF-1 $\alpha$ (Cayman, Ann Arbor, MI) or anti-HIF-2 $\alpha$ antibody (Santa Cruz Biotechnology) was added for supershift detection of the HIF-1 complex and incubated overnight at $4^{\circ} \mathrm{C}$. The products were analyzed by electrophoresis in $6 \%$ non-denaturing polyacrylamide gels. Electrophoresis was performed at 200 volts in $0.5 \mathrm{X}$ TBE buffer at $4^{\circ} \mathrm{C}$ for $2 \mathrm{~h}$. After electrophoresis, the gels were dried and subjected to autoradiography.

Chromatin immunoprecipitation (ChIP) assay. ChIP assay was performed using the ChIP-IT k $\mathrm{k}^{\mathrm{TM}}$ (Active Motif, Carlsbad, $\mathrm{CA}$ ), following the manufacturer's instructions, and using $2 \times 10^{7}$ Hepa1c1c7 or BPrC1 cells, under normoxic or hypoxic conditions. DNA-protein complexes were cross-linked in vivo with $1 \%$ final concentration of formaldehyde for $15 \mathrm{~min}$ at room temperature. The fixation reaction was stopped by adding Glycine Stop-Fix solution to a final concentration of $0.125 \mathrm{M}$ and rocking at room temperature for $5 \mathrm{~min}$. Cells were washed with ice-cold PBS and collected by centrifugation for $10 \mathrm{~min}$ at $2500 \mathrm{rpm}$ at $4^{\circ} \mathrm{C}$. Cells were resuspended in $1.5 \mathrm{ml}$ ice-cold lysis buffer (5 mM PIPES, pH 8.0, $85 \mathrm{mM}$ $\mathrm{KCl}, 0.5 \% \mathrm{NP}-40$ and protease inhibitors) and incubated on ice for $30 \mathrm{~min}$, then transferred to an ice-cold dounce homogenizer and dounced on ice with 10 strokes. Nuclei were pelleted by centrifugation for $10 \mathrm{~min}$ at $5,000 \mathrm{rpm}$ at $4^{\circ} \mathrm{C}$ followed by resuspension in $1 \mathrm{ml}$ shearing buffer $(50 \mathrm{mM}$ Tris- $\mathrm{HCl}, \mathrm{pH} 8.1,10 \mathrm{mM}$ EDTA, 1\% SDS and protease inhibitors). Input chromatin was generated by shearing the fixed chromatin into small (200-1000 bp), uniform pieces by sonication ( 9 intervals of $15 \mathrm{sec}, 2$ min resets between intervals, power setting 2 with Branson 3000 sonicator). Pre-clearing was performed by incubating input chromatin with protein $\mathrm{A} / \mathrm{G}$ agarose and rabbit or mouse $\mathrm{IgG}$ in ChIP dilution buffer (1\% Triton $\mathrm{X}-100,2 \mathrm{mM}$ EDTA, $20 \mathrm{mM}$ Tris-HCl, pH 8.1 and $150 \mathrm{~mm} \mathrm{NaCl}$ ) for $2 \mathrm{~h}$ at $4^{\circ} \mathrm{C}$. DNA-protein complexes were immunoprecipitated with specific antibody from input chromatin overnight at $4^{\circ} \mathrm{C}$. Protein $\mathrm{A} / \mathrm{G}$ agarose was added to precipitate the immune complexes for $5 \mathrm{~h}$ at $4^{\circ} \mathrm{C}$. Immunoprecipitation with $\mathrm{IgG}$ was used as a negative control to demonstrate antibody specificity. Immunoprecipitates were washed with a series of buffers $(1 \mathrm{ml}$ each wash with rocking for $10 \mathrm{~min}$ at $4^{\circ} \mathrm{C}$ ) as follows: one wash with low salt wash buffer $(0.1 \%$ SDS, $1 \%$ Triton X-100, 2 mM EDTA, $20 \mathrm{mM}$ Tris- $\mathrm{HCl}, \mathrm{pH} 8.1,150 \mathrm{mM} \mathrm{NaCl}$ ); four washes with high salt wash buffer $(0.1 \%$ SDS, $1 \%$ Triton X-100, 2 mM EDTA, $20 \mathrm{mM}$ Tris- $\mathrm{HCl}, \mathrm{pH} 8.1,500 \mathrm{mM} \mathrm{NaCl}$ ); one wash with $\mathrm{LiCl}$ wash buffer $(0.25 \mathrm{M} \mathrm{LiCl}, 1 \% \mathrm{NP}-40,1 \%$ deoxycholate, $1 \mathrm{mM}$ EDTA, $10 \mathrm{mM}$ Tris-HCl, $\mathrm{pH}$ 8.1); two washes with TE buffer. Immunoprecipitated DNA-protein complexes were eluted from the protein $\mathrm{A} / \mathrm{G}$ agarose with $1 \%$ SDS and $0.1 \mathrm{M}$ $\mathrm{NaHCO}_{3}$. The formaldehyde cross-links of the immunoprecipitated DNA-protein complexes were reversed by adding $5 \mathrm{M} \mathrm{NaCl}$ and $1 \mu 1$ of RNase A. The cross-links were also reversed in a portion of precleared input chromatin that had not been subjected to immunoprecipitation to generate input DNA. DNA was gel-purified using a PCR purification kit (Qiagen, Valencia, CA). Input DNA (diluted 200-fold) and DNA immunoprecipitated with specific antibodies or IgG were PCRamplified using primers flanking the $P A I-1$ promoter primers from -3743 to -3474 bp (-3743 primer: 5'-GCAGGGGACAG 
A

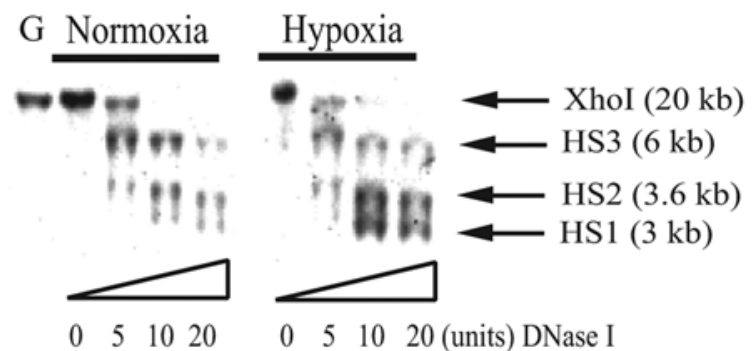

B

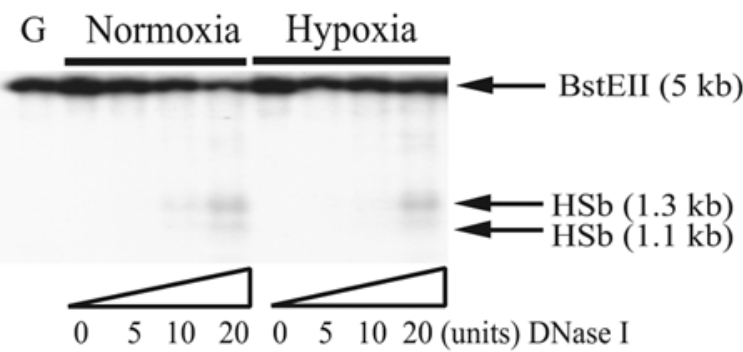

C

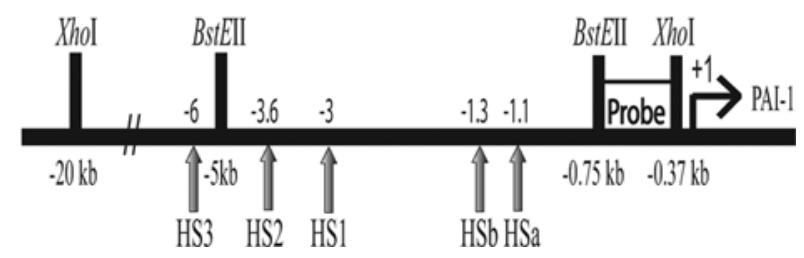

Figure 2. DNAse I HSs on the 5'-flanking promoter region of PAI-1 gene Nuclei were isolated from Hepa1c1c7 cells (normoxia or hypoxia, $4 \mathrm{~h}$ ) and aliquots of $\sim 10^{7}$ nuclei digested with DNAse I $(0,5,10,20 \mathrm{U})$ for $90 \mathrm{sec}$ at $20^{\circ} \mathrm{C}$. Genomic DNA was then purified and restriction digested with (A) XhoI $\left(4 \mathrm{~h}, 37^{\circ} \mathrm{C}\right)$ or $(\mathrm{B}) \mathrm{Bst} \mathrm{EII}\left(4 \mathrm{~h}, 60^{\circ} \mathrm{C}\right)$. DNA was electrophoresed on a $1 \%$ agarose gel, then Southern blotted and hybridized with BstEII/Xhol probe $(\mathrm{C})$ at $60^{\circ} \mathrm{C}$. Non-DNAse I digested genomic DNA $(\mathrm{G})$ was used as a positive control in the Southern blot. (C) Schematic representation of DNAse I HSs on the murine PAI-1 promoter.

TCATGGAA-3' and -3474 primer: 5'-AAAACCACTTTG ACCTCATC-3'), relative to the transcriptional start site at +1 . As a negative control, two primers (5'-ATGGTTGCCA CTGGGGATCT and 5'-TGCCAAAGCCTAGGGGAAGA) for the flanking region between $G A P D H$ and $C N A P 1$ (chromosome condensation-related SMC-associated protein) gene were used following the manufacturer's instructions. PCR amplification was performed with an initial melt step at $94^{\circ} \mathrm{C}$ for $5 \mathrm{~min}$, then $24-30$ cycles of $94^{\circ} \mathrm{C}$ for $45 \mathrm{sec}, 56^{\circ} \mathrm{C}$ for $30 \mathrm{sec}$ and $72^{\circ} \mathrm{C}$ for $60 \mathrm{sec}$ followed by $72^{\circ} \mathrm{C}$ for $10 \mathrm{~min}$. Products were analyzed by electrophoresis on a $2 \%$ agarose gel.

\section{Results}

Hypoxia induces the accumulation of PAI-1 $\mathrm{mRNA}$ and protein in an Arnt-dependent manner in mouse hepatoma cells. Preliminary observations indicated the induction of PAI-1 in the rat hepatocyte (8) and human hepatoma cell line HepG2 (9) in response to hypoxia. We therefore further analyzed the expression pattern of PAI-1 when exposed to hypoxia, using Arnt-positive mouse hepatoma cell line (Hepa1c1c7) and its Arnt-deficient variant $\left(\mathrm{BP}^{\mathrm{r}} \mathrm{C} 1\right)$ by Northern blotting (Fig. 1A) and Western blotting (Fig. 1B). The PAI-1 mRNA and protein were constitutively expressed albeit at low levels in Hepa1c1c7 cells, and its expression was markedly enhanced after exposure to hypoxia $\left(2 \% \mathrm{O}_{2}\right)$ for $24 \mathrm{~h}$. Hypoxia induced the accumulation of PAI-1 mRNA and protein via an Arnt-dependent mechanism (Fig. 1A and B): PAI-1 mRNA and protein were induced in Hepa1c1c7 cells exposed to hypoxia, whereas this induction was not observed in $\mathrm{BP}^{\mathrm{C}} \mathrm{C} 1$ ( $\mathrm{Arnt}^{-/}$) cells. Thus, as with the regulation of other hypoxia-activated genes (25), Arnt (HIF-1B) is an absolute requirement for PAI-1 induction by hypoxia. In the $\mathrm{BP}^{\mathrm{r}} \mathrm{C} 1\left(\mathrm{Arnt}^{--}\right)$cells, the absence of the critical partner Arnt abolished the hypoxia-induced PAI-1 expression.

DNAse I-hypersensitive sites were identified in the 5'-upstream promoter region of PAI-1 gene in response to normoxia and hypoxia. We used the DNAse I hypersensitivity technique to find protein-DNA interaction sites on the promoter region of the mouse $P A I-1$ gene. This technique is based on the assumption that proteins binding to the response elements will alter the chromatin structure in such a way as to increase the susceptibility of neighbouring regions to cleavage by DNAse I. Genomic Southern blotting identified a 20-kb XhoI band 5'-upstream of the transcription start site (Fig. 2A and C). Thus, we used this restriction enzyme to determine the presence of hypersensitive site (HS) (26) within this $\sim 20 \mathrm{~kb}$ of the PAI- 1 gene. Using XhoI (Fig. 2A), three HSs (marked as HS1, HS2 and HS3) were detected at about $-3,-3.6$ and $-6 \mathrm{~kb}$ 5 -upstream of the transcription start site in un-induced, or hypoxia-induced Hepa1c1c7 cells, respectively, suggesting that these sites are important in both basal and inducible expression of the constitutively expressed PAI-1 gene. Moreover, enhanced protein-DNA interactions were observed at -3.6 and $-3 \mathrm{~kb}$ in the hypoxia-induced cells (Fig. 2A), indicating the likely occupancy of HIF-1 in these two regions in response to hypoxia. Using $B s t$ EII digestion, two HS sites ( $\mathrm{HSa}$ and $\mathrm{HSb}$ ) were observed at about -1.1 and $-1.3 \mathrm{~kb}$ 5 -upstream of the transcription start site in un-induced and hypoxia-induced Hepa1c1c7 cells, suggesting that no additional protein-DNA interaction occurs at these sites under hypoxic conditions (Fig. 2B). The HSa and HSb sites likely correspond to regions flanking the $\mathrm{Sp} 1$ and BHLTF (helicase-like transcription factor) sites (27), indicating protein occupancy at these DNA motifs in the un-induced and induced states. No HS site was detected in the 3'-region of PAI-1 gene examined (data not shown). These results suggest that DNAse I HSs at $-3.6 \mathrm{~kb}$ and $-3 \mathrm{~kb}$ of the 5'-flanking promoter region of $P A I-1$ gene are important for inducible expression of the $P A I-1$ gene under hypoxia.

The presence of functional HREs on the promoter region of mouse PAI-1 gene in Hepalclc7 cells. We cloned a series of the $P A I-1$ promoter fragments encompassing the HS sites and subcloned them into the luciferase reporter gene assay vector. The plasmids were called pGL3-5HS, pGL3-4HS and pGL32HS and used for determining functional HRE(s) on the PAI- 1 promoter region in response to hypoxia (Fig. 3). As sequences beyond the $-1 \mathrm{~kb}$ region of PAI- 1 gene were not available, a 

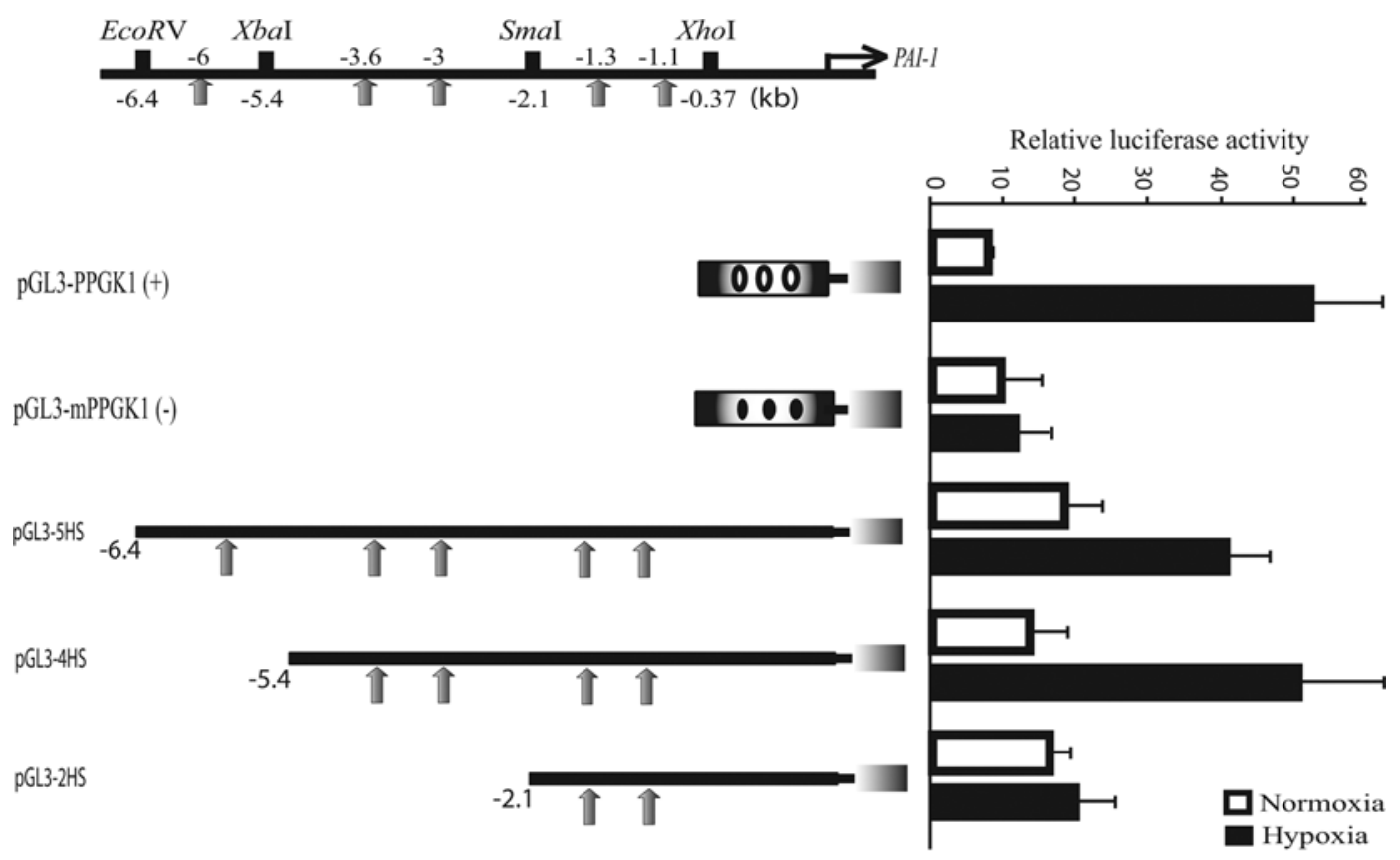

Luc $\quad$ : HRE $\quad$ : HRE mutant

Figure 3. Relationship between luciferase activity and DNAse I HS of PAI-1 promoter construct. Upper panel, restriction enzyme mapping of 5'-flanking promoter region of $P A I-1$ gene up to the $-6.4 \mathrm{~kb}$ from transcription start site is shown. Five thick arrows at $-6,-5.4,-3.6,-3,-1.3$ and $-1.1 \mathrm{~kb}$ indicate the DNAse I HSs. Lower panel, luciferase activities of three plasmids (pGL3-5HS, pGL3-4HS and pGL3-2HS), containing different DNAse I number of HSs under normoxia or hypoxia. pGL3-PPGK1, as a positive control and pGL3-mPPGK1, as a negative control were used. Data represent the mean \pm standard deviation of three independent experiments.

large piece of phage DNA containing the PAI-1 gene $(55 \mathrm{~kb})$ was isolated by using lambda plague screening assay with the mouse lambda genomic library and a probe described in the Materials and methods. For the functional analysis of these PAI-1 constructs in the Hepa1c1c7 cells, we used the luciferase reporter assay to test the endogenous HIF activity induced in hypoxia against these reporter constructs (Fig. 3). As a positive control, we used the promoter of $P G K 1$ and pGL3 basic vector (pGL3-PPGK1) which consists of the HREs of the $P G K-1$ gene ligated to the pGL3 basic vector since HIF has been reported to bind to the HREs of $P G K-1$ in the Hepa1c1c7 cells under hypoxia (23). As a negative control, a non-functional mutant mPPGK1-pGL3 construct (pGL3mPPGK1) was used since it could not associate with HIF protein. The pGL3-4HS construct, containng four HSs at $-3.6,-3,-1.3$ and $-1.1 \mathrm{~kb}$, showed the highest induction of luciferase activity. The pGL3-5HS and pGL3-2HS constructs, containing five HSs and two HSs respectively, did not show greater luciferase activity than pGL-4HS, indicating that HSs at $-6,-1.3$ and -1.1 were less important sites for protein-DNA interactions under hypoxia (Fig. 3). We therefore infer that the DNAse I HSs at -3.6 and $-3 \mathrm{~kb}$ are most critical for hypoxia-induced reporter gene activity, consistent with the result of the DNAse I hypersensitivity assay (Fig. 2A).

-3.6- and -3-kb promoter regions of PAI-1 gene contain enhancer activity in Hepalclc7 cells under hypoxia. Because the tested 5'-flanking promoter region of PAI-1 gene (pGL34HS) showed the greatest luciferase activity under hypoxia (Fig. 3), this region might contain regulatory elements important for hypoxia-induced gene expression. We therefore sequenced the region between the EcoRV (-6.4 kb) and XhoI sites $(-0.3 \mathrm{~kb})$ at the 5 '-promoter region of the PAI- 1 gene and identified putative consensus sequences for HREs (RCGTG, $\mathrm{R}=\mathrm{A} / \mathrm{G}$ ). According to our sequence (DDBJ accession no. AB331006), a total of seven putative HREs could be found from -3845 to -3000 bp (Fig. 4A). To further analyze these putative HREs, this DNA fragment and two shorter DNA fragments (from -6.4 to-5.4 kb and -3136 to $-2985 \mathrm{bp}$ ), each containing different putative HREs were made by PCR, and each ligated with pGL3 promoter vector to give pGL3-EX, pGL3-XS, pGL3-HS(-3) and pGL3-HS(-3.6) (Fig. 4B). To distinguish which HIF molecule activates the putative HREs, HIF-1 or HIF-2 expression vector was used in an overexpression system. The plasmid constructs with greater luciferase activity with HIF-1 or HIF-2 overexpression vector were pGL3-XS and pGL3-HS(-3.6) (Fig. 4B). The pGL3-HS(-3) and pGL3-EX constructs that lack HRE elements did not show markedly enhanced luciferase activity ( $\sim 1.5$-fold induction) despite having putative HREs. Therefore, the DNAse I HS at $-3.6 \mathrm{~kb}$ possesses enhancer activity in response to HIF-1 or HIF-2 under hypoxia.

To identify which of the HREs within pGL3-HS(-3.6) has transcriptional enhancing activity, four mutants (RCGTG $\rightarrow$ TTTTG) were constructed [HS(-3.6)M1, HS(-3.6)M2, HS (-3.6)M3, HS(-3.6)M4 and HS(-3.6)M5] and each ligated with pGL3 promoter (Fig. 4B). The relative luciferase activities of pGL3-HS(-3.6)M1, pGL3-HS(-3.6)M2 and HS(-3.6)M5 were significantly reduced compared to that of pGL3-3.6HS, pGL3-HS(-3.6)M3 and HS(-3.6)M4. Therefore, the two HREs located at -3625 and -3616 are essential for inducing $P A I-1$ gene expression under hypoxia. 


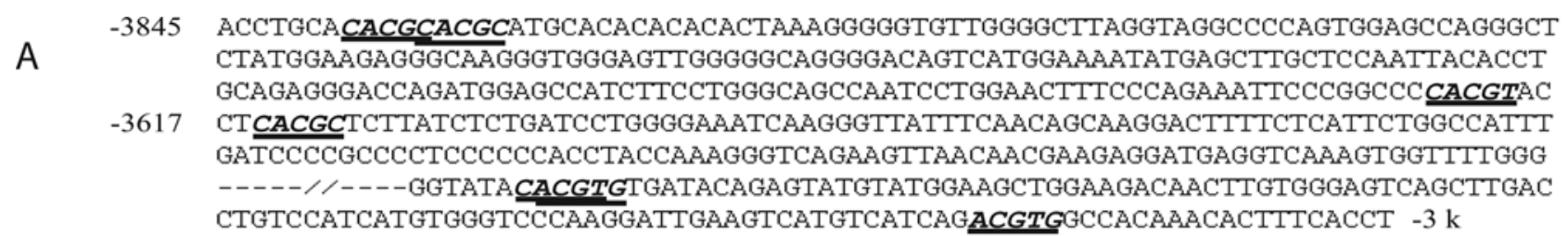

B

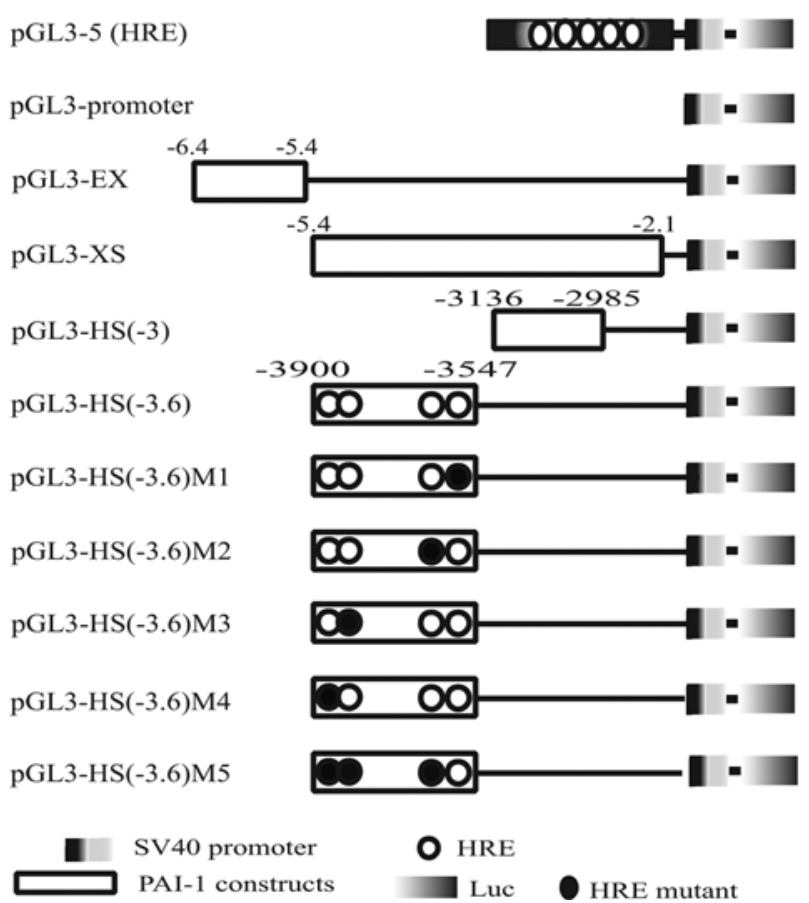

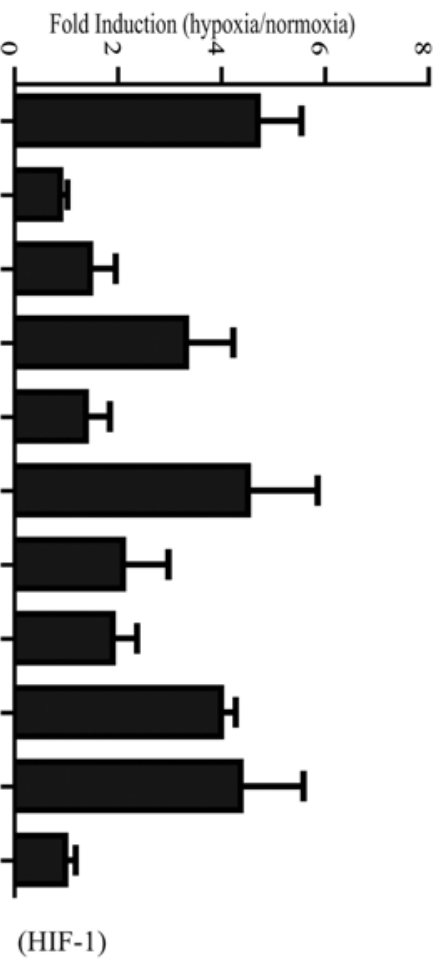

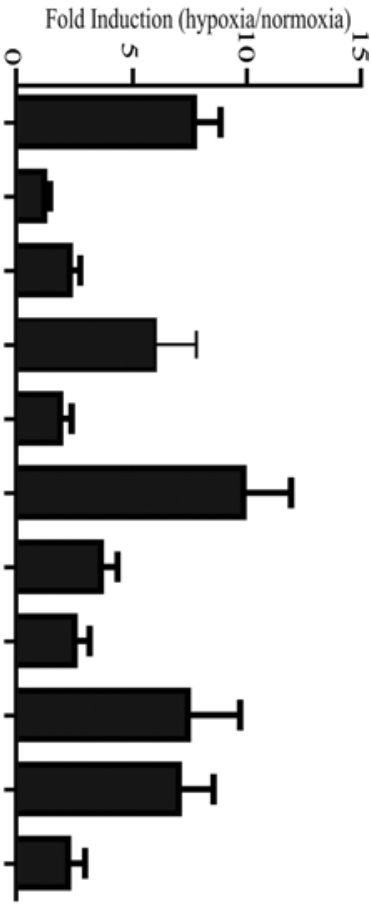

(HIF-2)

Figure 4. Luciferase reporter assay with transcriptional enhancement of PAI-1 constructs by HIF-1 or HIF-2 overexpression. (A) The sequence of PAI-1 promoter from -3845 to $-3 \mathrm{~kb}$. Italics and underline indicate that HRE (RCGTG, R=A/G) on the sequences. (B) Several PAI-1-derived constructs were made as described in Materials and methods. The positive control was pGL3-5 (HRE), which consists of 5 HREs ligated to the pGL3 promoter vector, and the negative control was pGL3-promoter. For studies on hypoxia-inducibility, transfected Hepa1c1c7 cells were exposed to $1.3-2 \% \mathrm{O}_{2}$ for 24 h, and then harvested for measurement of reporter gene activities. Data represent the mean \pm standard deviation of three independent experiments.

HIF-1 or HIF-2 protein associate with HREs at -3625 and -3616 bp of PAI-1 gene. To confirm any association between HIF-1 protein and the functional HREs identified through our reporter gene assays, we characterized protein-DNA interactions in situ by LM-PCR mediated in vivo footprinting (Fig. 5), EMSA and ChIP assays (Fig. 6). Hepa1c1c7 and $\mathrm{BP}^{\mathrm{r}} \mathrm{C} 1$ cells cultured under normoxia or hypoxia were treated with DMS-piperidine (lanes 1-5) or DNAse I (lanes 6-10), and their DNAs were isolated for LM-PCR. The amplified products of LM-PCR were analyzed using $8 \%$ sequencing gels. Naked genomic DNA treated with both agents in vitro was analyzed as controls (lanes 1 and 6). In lanes 2 and 3, we observed typical footprinting patterns in Hepa1c1c7 cells cultured under hypoxia compared to those cultured under normoxia. The footprints produced by DMS-piperidine represent the HREs (lane 3). The use of DNAse I generated a similar, but broader footprinting pattern (lane 8) compared to that produced by DMS-piperidine; the sequence of the footprint is shown in Fig. 5B. In the $\mathrm{BP}^{\mathrm{r}} \mathrm{C} 1$ cells cultured under normoxia or hypoxia, the typical footprinting patterns were not observed in either the DMS-piperidine (lanes 4 and 5) or DNAse I (lanes 9 and 10) method, suggesting that
HIF proteins are not involved in the occupancy of the HRE sites in $\mathrm{BP}^{\mathrm{r}} \mathrm{C} 1$ cells.

In order to investigate which HIF protein is involved in binding to the identified HREs, EMSA with antibody supershift assay was carried out (Fig. 6A). We observed that the transcription factors ATF and CREB bind constitutively to the probe (lanes 1, 2 and 3) (28). The decreased intensities of the HIF band in lanes 2 and 3 suggest that both HIF-1 and HIF-2 proteins bound to the probe; in particular the strongly supershifted band in lane 2 suggest that HIF-2 is the predominant protein responsible for HIF/HRE interaction at -3625 and -3616 bp of PAI-1 promoter.

To further demonstrate the in vivo significance of HIF proteins and its binding to the HRE of the PAI-1 promoter, ChIP assay (Fig. 6B) was performed with antibodies recognizing HIF- $1 \alpha$ or HIF-2 $\alpha$. DNA was amplified with primers from -3743 to -3474 bp that includes HREs at -3625 and -3616 bp of PAI- 1 gene. Some PCR product with HIF- $1 \alpha$ and HIF- $2 \alpha$ antibodies were detectable in Hepa1c1c7 cells under normoxia and hypoxia, but levels markedly increased under hypoxia, especially with HIF- $2 \alpha$ antibody,which is consistent with EMSA data. No PCR product was detectable in the 
A

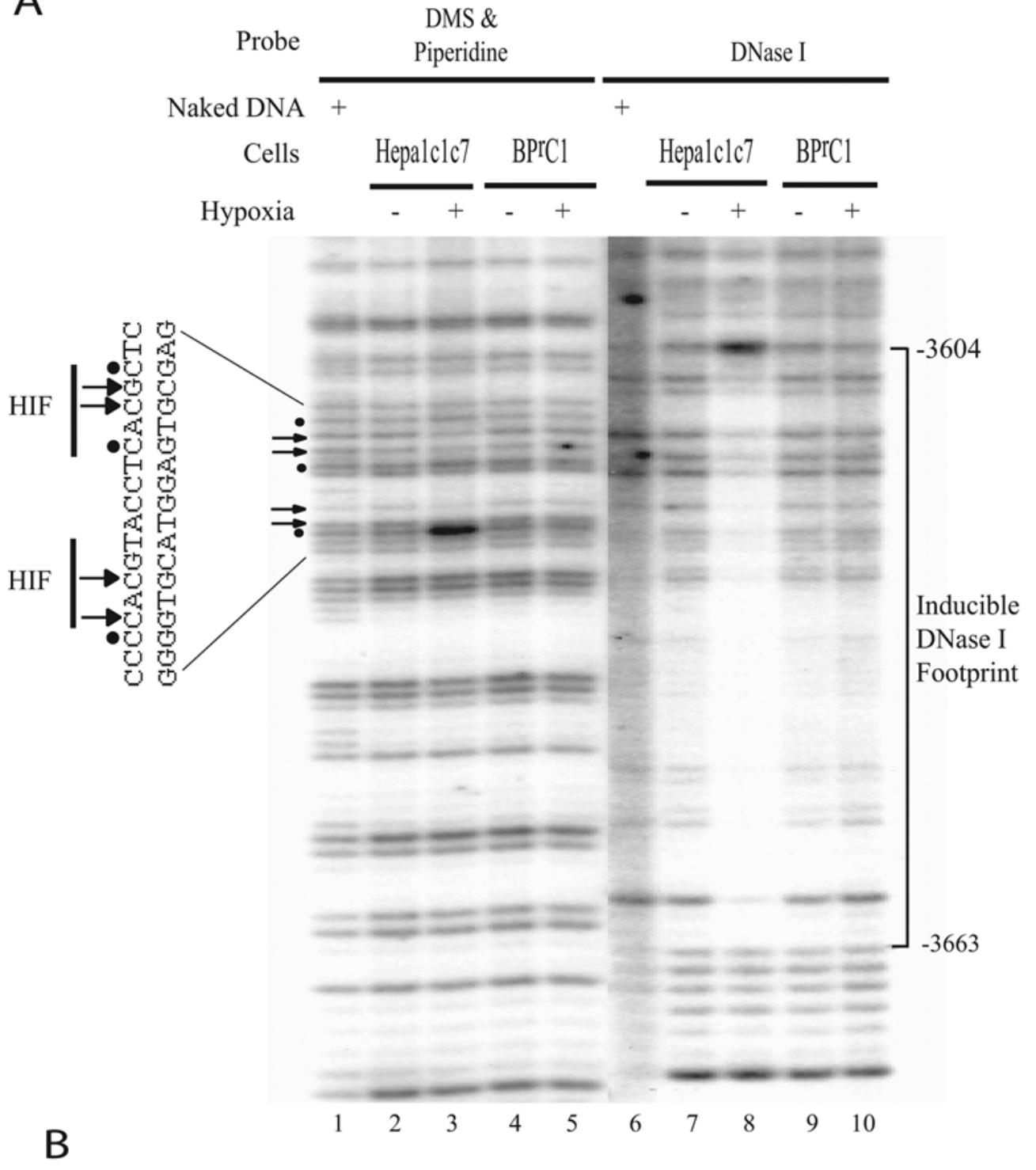

Figure 5. In vivo footprinting analysis to identify protein-DNA interactions on the HREs of PAI-1 gene. Hepa1c1c7 (Arnt ${ }^{+/+}$) cells and its Arnt-deficient variant cells $(\mathrm{BP} C 1)$ were cultured under the normoxia $\left(20 \% \mathrm{O}_{2}\right)$ or hypoxia $\left(2 \% \mathrm{O}_{2}\right)$ for $24 \mathrm{~h}$. (A) Footprintings for protein-DNA interactions on the two HREs at -3604 and -3653 bp of PAI-1 promoter. After treatment with DMS-piperidine (lanes 2-5) or DNAse I (lanes 7-10), DNA was analyzed for proteinDNA interactions by LM-PCR. Naked genomic DNA treated with these agents in vitro was also analyzed (lanes 1 and 6). Numbers indicate distance (in basepairs) from the major transcription initiation site. Brackets indicate DNA regions protected from DNAse I digestion in hypoxic cells. Arrows indicate guanine residues protected from DMS modification in hypoxic cells. Bold circles indicate guanine residues hypersensitive to DMS modification in hypoxic cells. Lines indicate binding sites for HIF proteins. The LM-PCR products loaded in lane 8 was diluted 10 -fold to normalize banding intensity. (B) Nucleotide sequences indicating the footprints identified by in vivo footprintings. Bold characters (5-CACG or 5-CGTG) indicate the core binding sites of HRE. Arrows indicate guanine residues protected from DMS modification in footprints sequences. Bold circles indicate guanine residues hypersensitive to DMS modification in footprints sequences.

$\mathrm{BP}^{\mathrm{r}} \mathrm{C} 1$ cells under normoxia or hypoxia. In addition, no PCR product was amplified using control antibody or at a flank region between $G A P D H$ and $C N A P 1$ gene, demonstrating specificity. Taken together, our in vitro and in vivo data provide evidence that the two HREs at -3625 and -3616 bp of PAI-1 promoter can interact with both HIF-1 and HIF-2.

\section{Discussion}

Ischemia, inflammation and cancer give rise to low oxygen tension (hypoxia), which leads to the activation of HIF-1 or HIF-2 transcription factor in mammals. These HIF proteins act as transcriptional regulators that associate with HRE and 
A

$\begin{array}{rccccc}\text { P32-HRE DNA (hot) } & + & + & + & + & + \\ \text { Nuclear E xtracts } & + & + & + & + & + \\ \text { Anti-HIF-1 } \alpha \text { antibody } & - & - & + & - & - \\ \text { Anti-HIF-2 } \alpha \text { antibody } & - & + & - & - & - \\ \text { HRE DNA (cold) } & - & - & - & + & + \\ & & & & (\mathrm{X} 1000) & (\mathrm{X} 500)\end{array}$

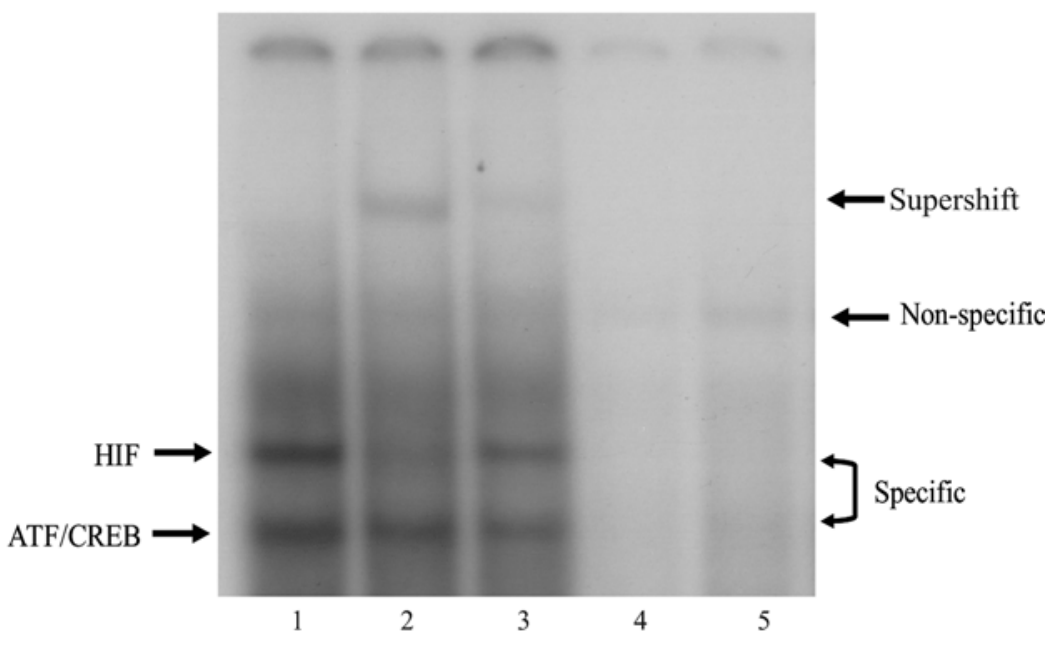

B

$\mathrm{C}$

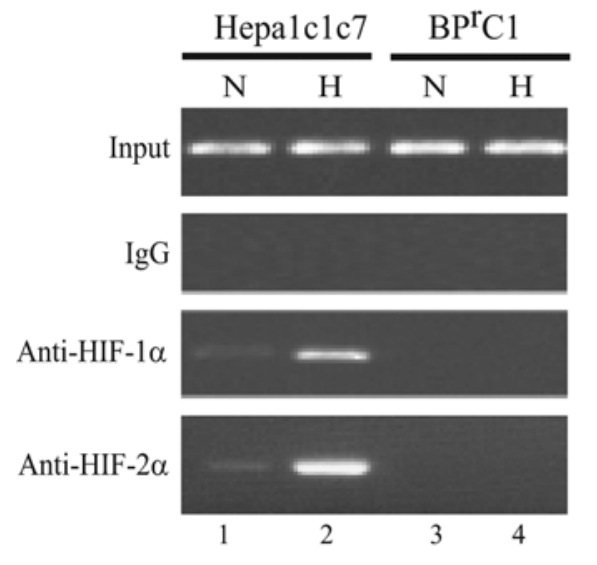

$-3.6 \mathrm{~kb}$ of PAI- 1 promoter region

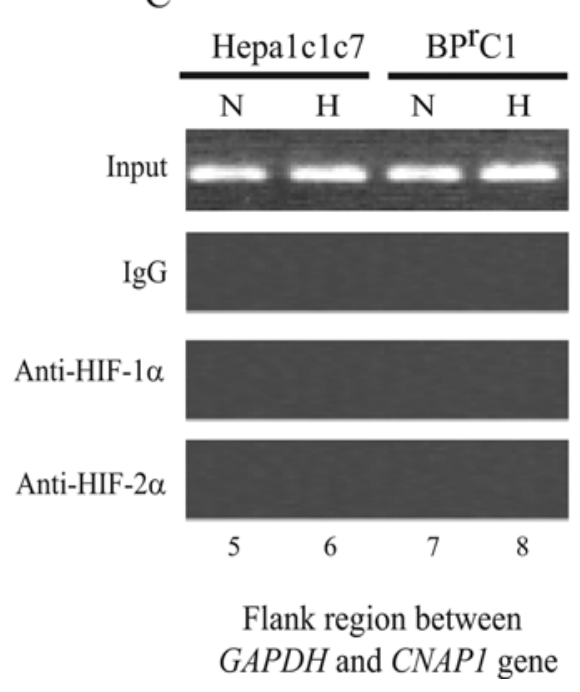

GAPDH and CNAPI gene

Figure 6. HIF proteins/HRE interactions on the -3743 to $-3474-b p$ region of the PAI-1 promoter by EMSA (A) and ChIP assays (B and C). (A) Hepa1c1c7 cells were exposed to hypoxia for $6 \mathrm{~h}$, nuclear extracts were then prepared and EMSA carried out as described in Materials and methods. Lane 1 shows that HIF proteins bound to the probe. HIF-2/DNA complex was detected in lane 2 and HIF-1/DNA complex was detected in lane 3 . Supershift assay showed that the HIF-2/DNA complex (lane 2) and the HIF-1/DNA complex (lane 3) were shifted up in the presence of oligo probe and $5 \mu \mathrm{g}$ HIF-1 $\alpha$ or $5 \mu \mathrm{g}$ HIF- $2 \alpha$ antiboby. The transcription factors ATF and CREB bind constitutively to the HIF DNA recognition site (lanes 1-3). Lanes 4 and 5 showed that a 500-fold (lane 4) and 250-fold (lane 5) excess of the indicated unlabeled (cold) oligonucleotide encompassing the HREs of PAI-1 was added. (B and C) Specific DNA/protein complexes were immunoprecipitated from cross-linked chromatin using a specific anti-HIF-1 $\alpha$ or anti-HIF-2 antibody and eluted DNA was PCR-amplified using the primer set described in Materials and methods. DNA eluted from unprecipitated chromatin was used as input DNA. As a negative control, the flank region between $G A P D H$ and $C N A P 1$ gene was used. N, normoxia; H, hypoxia.

control the expression of multiple genes involved in glycolysis (e.g. $P G K$ and $L D H A$ ), apoptosis (e.g. BNIP3), proliferation (e.g. $T G F \alpha$ and $C C D 1$ ), de-differentiation (e.g. Oct 4), angiogenesis (e.g. VEGF, Ang2, Fit1, Tie2) and invasion and metastasis (e. g. PAI-1, CXCR4, MMP2, Lox) (1).

In this report, we identified the enhancer elements essential in the hypoxia-mediated induction of PAI-1 gene expression in mouse Hepa1c1c7 cells using a combination of DNAse I hypersensitivity analysis and protein-DNA interaction analysis. The induction of PAI-1 under hypoxia $(7,8,12,29,30)$ together with a possible mechanism of its induction $(8,9,31)$ has been reported. Previous reports using reporter gene assay and EMSA revealed that the $-175 /-158$-bp region of the rat PAI-1 promoter (8) and the $-194 /-187-$ bp region of the 


\section{Mouse tcccaggatcagagataagagcgtgaggtacgtggggccgggaatttctg Rat tccccgggaccagagataagagcgtgagttacgtggggctgtggatttctg Human tccggagggtcagagataagagagtgagttac--cgggctgtggatttcag Orangutan tccggagagtcagagataagagagtgagttac--cgggctgtggatttcag Dog cccagagggtcagagataagagggtgaattac--aagagtatggattttct Horse ccgggagggtcagagataagaggatgagttac--agcgccgtgggtttctg Opossum cacagagtacagaagataagagaaccaattat--agagac-tagcttctg}

Figure 7. Species-specific HREs in the -3.6-kb regions of PAI-1 promoter. Nucleotide sequences of rodents, human and other mammals showing that functional HREs (RCGTG) in rodents are missing or mutated in the other mammals. This alignment is from UCSC genome browser on mouse July 2007 (NCBI37/mm9) assembly (http://genome.ucsc.edu/). Alignment sequence is chr5:137,551,750-137,551,800, $51 \mathrm{bp}$.

human $P A I-1$ promoter $(9,31)$ have functional HREs that can interact with HIF-1 to enhance PAI- 1 expression. Analysis of the reported mouse fibroblast $P A I-1$ gene sequence with the rat and human PAI-1 gene sequence shows that these HREs are conserved $(8,9)$. Our study extends previous observations by identifying additional HREs in the promoter of the PAI-I gene.

We first wanted to confirm the presence of the reported HREs in our mouse hepatoma cell line to characterize the core promoter of the PAI-1 gene in our cell system. However, our experiments showed that the HREs in this region of the mouse PAI-1 gene did not interact with HIF-1 protein (data not shown) and did not enhance luciferase activity in the reporter gene assay (Fig. 3, pGL3-2HS). These negative data imply that the conserved HREs might be non-functional in the mouse or Hepa1c1c7 cells for unknown reasons; therefore, functional HREs of the mouse Hepa1c1c7 cells might reside further upstream or downstream of these regions.

In order to find additional HRE(s), we used the DNAse I hypersensitivity assay to locate regions of the $P A I-1$ promoter that may be involved in the expression of $P A I-1$. We identified five HSs at about $-1.1,-1.3,-3,-3.6$ and $-6 \mathrm{~kb} 5$ '-upstream of the transcription start site in un-induced and hypoxia-induced Hepa1c1c7 cells, suggesting these sites to be important in both basal and inducible expression of PAI-1. Two of these HS sites, at 1.1 and $1.3 \mathrm{~kb} \mathrm{5'-upstream} \mathrm{of} \mathrm{the} \mathrm{transcription}$ start site, correspond to regions flanking the Sp1 and BHLTF sites, indicating protein occupancy at these DNA motifs in the un-induced and induced states. We observed basal PAI-1 expression under normoxia consistent with results stating that functional interactions at the Sp1 and BHLTF sites are essential for PAI-1 expression (27). Of particular interest are the HS sites at -3 and $-3.6 \mathrm{~kb} 5$ '-upstream of the transcription start site: while they are also present under normoxia, these sites are enhanced under hypoxia. This suggests that the putative HREs of the PAI-1 gene may be constitutively occupied and maintained in an accessible configuration which does not undergo major chromatin remodeling when stimulated by hypoxia, but increased protein-DNA interactions may occur under hypoxia.

Luciferase reporter gene assay with $P A I-1$ fragments suggested that the $-3.6-\mathrm{kb}$ region of the $P A I-1$ gene was able to enhance luciferase activity. Sequence analyses show the presence of a pair of contiguous HREs (-3633 GCCCCACG TACCTCACGCTCTTA -3611) in the mouse -3.6-kb region of PAI- 1 promoter. Mutation of either one or both HRE sites within the tested plasmid [pGL3-HS(-3.6)] resulted in complete loss of enhancer function. Therefore, both HREs within this $-3.6-\mathrm{kb}$ region of PAI-1 gene are essential for regulating mouse PAI-1 expression in response to hypoxia. In order to understand the molecular mechanism(s) leading from HIF proteins occupancy to transcription of the PAI-1 gene product, in vivo footprinting and in vivo ChIP assays were carried out at the $-3.6-\mathrm{kb}$ regions. The advantages of these assays are that they allow detection of protein-DNA interactions on endogenous genes in intact cells, and reflect gene regulation under in vivo conditions such as chromatin structure, and other regulatory macromolecules $(32,33)$. Our data demonstrated that HIF protein/HRE interactions can only occur in the Hepa1c1c7 cells, but not in the $\mathrm{BP}^{\mathrm{r}} \mathrm{C} 1$ cells, implying that the two HREs at the $-3.6-\mathrm{kb}$ region of PAI-1 promoter must be functional HREs. Although evolutionary conservation is a common criterion for the identification of functional regulatory elements, sequence comparisons in the identified HRE loci performed among mammals indicated that the identified HREs are conserved only in rodents, but not in humans or other mammals (Fig.7). Whatever the mechanism(s) by which HREs are lost or mutated among species, it appears that the identified HREs may be essential for gene regulation in response to hypoxia only in rodent and not in other species. This poses interesting question related to cancer therapy and evolutionary changes among species in response to hypoxia.

The expression of PAI-1 gene under normoxia and hypoxia varies among cell lines $(8,29,30,34)$. The mouse hepatoma (Hepa1c1c7) and its Arnt-deficient variant $\left(\mathrm{BP}^{\mathrm{r}} \mathrm{C} 1\right)$ cells provide a useful system for our study because PAI-1 mRNA and protein were observed in Hepa1c1c7 cells under normoxia and hypoxia, but was not observed in the $\mathrm{BP}^{\mathrm{r}} \mathrm{C} 1$ cells. The mechanism of PAI- 1 expression under normoxia is mediated by interactions between SP1 or SP3 and the helicase-like transcription factor, homologous to chromatin remodeling proteins (27). Under normoxia, two prolines of HIF-1 $\alpha$ oxygen-dependent degradation domain (ODD) are hydroxylated by a family of oxygen-dependent proline hydroxylases, which then associate with von Hippel-Lindau (VHL) protein and are degraded via the ubiquitin pathway $(5,35,36)$. This does not occur under hypoxia, thereby stabilizing the HIF- $1 \alpha$ or HIF- $2 \alpha$ proteins and allowing it with HIF- $\beta$ to recruit p300/CBP for chromatin remodeling and leading to the expression of target genes (37). Therefore, interaction of HIF-1 or HIF-2 with the HRE is required for the induction of PAI-1 expression under hypoxia. In our system, although HIF- $2 \alpha$ appears to be more strongly bound to the identified HREs than HIF-1 $\alpha$, both HIF-1 and HIF-2 seem to be involved in PAI-1 transcription. Consistently HIF-2 was reported to primarily regulate $P A I-1$ transcription in response to hypoxia in MCF-7 (38) and A549 cells (39).

Hypoxia is prevalent in solid tumors, and the activity of HIF proteins in response to hypoxia regulates multiple genes that enhance tumor metastasis and angiogenesis. Thus, the disruption of the HIF signaling pathway has been studied as an attractive strategy for cancer therapy (40). A dominant negative HIF-1 $\alpha$ has been shown to reduce tumorigenicity of pancreatic cancer (41). In addition, many small molecular 
inhibitors of the HIF signaling pathway have been discovered and used to inhibit the expression of HIF target genes to reduce angiogenesis and metastasis (42). Another approach involves the direct inhibition of p300/CBP (43) and DNA binding activity (44) to repress the HIF target genes. Thus, the newly identified HREs in hepatoma cells might provide a good model to study cancer treatment.

In conclusion, we have identified two HREs at $-3.6 \mathrm{~kb}$ of the 5'-flanking promoter region of the PAI-1 gene that can function as cis-acting elements to regulate $P A I-1$ gene induction by hypoxia. We also provided evidence of interaction of these HREs with HIF-1 or HIF-2 protein, which helps to explain the mechanism of how HIF-1or HIF-2 mediates PAI-1 gene transcription in the mouse hepatoma cells. Given the importance of hypoxia, HIF-1, HIF-2 and PAI-1 in solid tumors, the targeting of this signaling pathway offers a potentially valuable strategy for the clinical management of these tumors.

\section{Acknowledgements}

This work was supported by the Korea Research Foundation (KRF-2003-070-C00033), and 2008 PNU-IGB Joint Research Center Grant of Pusan National University.

\section{References}

1. Gordan JD and Simon MC: Hypoxia-inducible factors: Central regulators of the tumor phenotype. Curr Opin Genet Dev 17: 71-77, 2007

2. Gu YZ, Hogenesch JB and Bradfield CA: The PAS superfamily: Sensors of environmental and developmental signals. Annu Rev Pharmacol Toxicol 40: 519-561, 2000.

3. Crews ST and Fan CM: Remembrance of things PAS: Regulation of development by bHLH-PAS proteins. Curr Opin Genet Dev 9: 580-587, 1999.

4. Semenza GL: Expression of hypoxia-inducible factor 1: Mechanisms and consequences. Biochem Pharmacol 59: 47-53, 2000.

5. Ke Q and Costa M: Hypoxia-inducible factor-1 (HIF-1). Mol Pharmacol 70: 1469-1480, 2006.

6. Semenza GL: HIF-1: Mediator of physiological and pathophysiological responses to hypoxia. J Appl Physiol 88: 1474-1480, 2000.

7. Pinsky DJ, Liao H, Lawson CA, et al: Coordinated induction of plasminogen activator inhibitor-1 (PAI-1) and inhibition of plasminogen activator gene expression by hypoxia promotes pulmonary vascular fibrin deposition. J Clin Invest 102: 919-928, 1998.

8. Kietzmann $\mathrm{T}$, Roth $\mathrm{U}$ and Jungermann $\mathrm{K}$ : Induction of the plasminogen activator inhibitor-1 gene expression by mild hypoxia via a hypoxia response element binding the hypoxiainducible factor-1 in rat hepatocytes. Blood 94: 4177-4185, 1999.

9. Fink T, Kazlauskas A, Poellinger L, Ebbesen P and Zachar V: Identification of a tightly regulated hypoxia-response element in the promoter of human plasminogen activator inhibitor-1. Blood 99: 2077-2083, 2002.

10. Samoylenko A, Roth U, Jungermann K and Kietzmann T: The upstream stimulatory factor-2a inhibits plasminogen activator inhibitor-1 gene expression by binding to a promoter element adjacent to the hypoxia-inducible factor-1 binding site. Blood 97: 2657-2666, 2001.

11. Gorlach A, Diebold I, Schini-Kerth VB, et al: Thrombin activates the hypoxia-inducible factor-1 signaling pathway in vascular smooth muscle cells: Role of the p22(phox)-containing NADPH oxidase. Circ Res 89: 47-54, 2001.

12. Dietzmann K, von Bossanyi P, Krause D, Wittig H, Mawrin C and Kirches E: Expression of the plasminogen activator system and the inhibitors PAI-1 and PAI-2 in posttraumatic lesions of the cns and brain injuries following dramatic circulatory arrests: An immunohistochemical study. Pathol Res Pract 196: 15-21, 2000 .
13. Agirbasli M: Pivotal role of plasminogen-activator inhibitor 1 in vascular disease. Int J Clin Pract 59: 102-106, 2005.

14. Frandsen TL, Holst-Hansen C, Nielsen BS, et al: Direct evidence of the importance of stromal urokinase plasminogen activator (UPA) in the growth of an experimental human breast cancer using a combined uPA gene-disrupted and immunodeficient xenograft model. Cancer Res 61: 532-537, 2001.

15. Almholt K, Nielsen BS, Frandsen TL, Brunner N, Dano K and Johnsen M: Metastasis of transgenic breast cancer in plasminogen activator inhibitor-1 gene-deficient mice. Oncogene 22: 4389-4397, 2003.

16. Bajou K, Masson V, Gerard RD, et al: The plasminogen activator inhibitor PAI-1 controls in vivo tumor vascularization by interaction with proteases, not vitronectin. Implications for antiangiogenic strategies. J Cell Biol 152: 777-784, 2001.

17. Kwaan HC, Wang J, Svoboda K and Declerck PJ: Plasminogen activator inhibitor 1 may promote tumour growth through inhibition of apoptosis. Br J Cancer 82: 1702-1708, 2000.

18. Prendergast GC, Diamond LE, Dahl D and Cole MD: The c-mycregulated gene mrl encodes plasminogen activator inhibitor 1 . Mol Cell Biol 10: 1265-1269, 1990

19. Kunz C, Pebler S, Otte J and von der Ahe D: Differential regulation of plasminogen activator and inhibitor gene transcription by the tumor suppressor p53. Nucleic Acids Res 23: 3710-3717, 1995.

20. Pappot H, Pedersen AN, Brunner N and Christensen IJ: The complex between urokinase (uPA) and its type- 1 inhibitor (PAI-1) in pulmonary adenocarcinoma: Relation to prognosis. Lung Cancer 51: 193-200, 2006.

21. Sternlicht MD, Dunning AM, Moore DH, et al: Prognostic value of PAI1 in invasive breast cancer: Evidence that tumorspecific factors are more important than genetic variation in regulating PAI1 expression. Cancer Epidemiol Biomarkers Prev 15: 2107-2114, 2006

22. Osmak M, Niksic D, Brozovic A, Ristov AA, Vrhovec I and Skrk J: Drug resistant tumor cells have increased levels of tumor markers for invasion and metastasis. Anticancer Res 19: 3193-3197, 1999.

23. Okino ST, Chichester $\mathrm{CH}$ and Whitlock JP Jr: Hypoxiainducible mammalian gene expression analyzed in vivo at a tata-driven promoter and at an initiator-driven promoter. J Biol Chem 273: 23837-23843, 1998.

24. Okino ST and Whitlock JP Jr: Cytochrome p450 gene regulation. Analysis of protein-DNA interactions in situ. Methods Mol Biol 107: 395-404, 1998.

25. Salceda S, Beck I and Caro J: Absolute requirement of aryl hydrocarbon receptor nuclear translocator protein for gene activation by hypoxia. Arch Biochem Biophys 334: 389-394, 1996.

26. Dachs GU and Tozer GM: Hypoxia modulated gene expression: Angiogenesis, metastasis and therapeutic exploitation. Eur J Cancer 36: 1649-1660, 2000.

27. Ding H, Benotmane AM, Suske G, Collen D and Belayew A: Functional interactions between Sp1 or Sp3 and the helicaselike transcription factor mediate basal expression from the human plasminogen activator inhibitor-1 gene. J Biol Chem 274: 19573-19580, 1999

28. Kvietikova I, Wenger RH, Marti HH and Gassmann M: The transcription factors ATF- 1 and CREB- 1 bind constitutively to the hypoxia-inducible factor-1 (HIF-1) DNA recognition site. Nucleic Acids Res 23: 4542-4550, 1995.

29. Hopkins WE, Westerhausen DR, Fujii S, Billadello JJ and Sobel BE: Mediators of induction of augmented expression of plasminogen activator inhibitor type-1 in Hep $\mathrm{G} 2$ cells by platelets. Thromb Haemost 66: 239-245, 1991.

30. Kimura D, Imaizumi T, Tamo W, et al: Hypoxia enhances the expression of plasminogen activator inhibitor-1 in human lung cancer cells, EBC-1. Tohoku J Exp Med 196: 259-267, 2002.

31. Liao H, Hyman MC, Lawrence DA and Pinsky DJ: Molecular regulation of the PAI-1 gene by hypoxia: Contributions of Egr-1, HIF-1alpha, and C/EBPalpha. FASEB J 21: 935-949, 2007.

32. Kuo MH and Allis CD: In vivo cross-linking and immunoprecipitation for studying dynamic protein:DNA associations in a chromatin environment. Methods 19: 425-433, 1999.

33. Mueller PR and Wold B: In vivo footprinting of a muscle-specific enhancer by ligation mediated PCR. Science 246: 780-786, 1989.

34. Wojta J, Kaun C, Breuss JM, et al: Hepatocyte growth factor increases expression of vascular endothelial growth factor and plasminogen activator inhibitor-1 in human keratinocytes and the vascular endothelial growth factor receptor flk-1 in human endothelial cells. Lab Invest 79: 427-438, 1999. 
35. Jaakkola P, Mole DR, Tian YM, et al: Targeting of HIF-alpha to the von Hippel-Lindau ubiquitylation complex by $\mathrm{O}_{2}$ regulated prolyl hydroxylation. Science 292: 468-472, 2001

36. Yu F, White SB, Zhao Q and Lee FS: HIF-1alpha binding to VHL is regulated by stimulus-sensitive proline hydroxylation. Proc Natl Acad Sci USA 98: 9630-9635, 2001.

37. Kasper LH and Brindle PK: Mammalian gene expression program resiliency: The roles of multiple coactivator mechanism in hypoxia-responsive transcription. Cell Cycle 5: 142-146, 2006.

38. Carroll VA and Ashcroft M: Role of hypoxia-inducible factor (HIF)-1alpha versus HIF-2alpha in the regulation of HIF target genes in response to hypoxia, insulin-like growth factor-I, or loss of von Hippel-Lindau function: Implications for targeting the HIF pathway. Cancer Res 66: 6264-6270, 2006.

39. Sato M, Tanaka T, Maemura K, et al: The PAI-1 gene as a direct target of endothelial PAS domain protein-1 in adenocarcinoma A549 cells. Am J Respir Cell Mol Biol 31: 209-215, 2004.
40. Semenza GL: Targeting HIF-1 for cancer therapy. Nat Rev Cancer 3: 721-732, 2003.

41. Chen J, Zhao S, Nakada K, et al: Dominant-negative hypoxiainducible factor-1 alpha reduces tumorigenicity of pancreatic cancer cells through the suppression of glucose metabolism. Am J Pathol 162: 1283-1291, 2003.

42. Rapisarda A, Uranchimeg B, Scudiero DA, et al: Identification of small molecule inhibitors of hypoxia-inducible factor 1 transcriptional activation pathway. Cancer Res 62: 4316-4324, 2002.

43. Kung AL, Zabludoff SD, France DS, et al: Small molecule blockade of transcriptional coactivation of the hypoxiainducible factor pathway. Cancer Cell 6: 33-43, 2004.

44. Kong D, Park EJ, Stephen AG, et al: Echinomycin, a smallmolecule inhibitor of hypoxia-inducible factor-1 DNA-binding activity. Cancer Res 65: 9047-9055, 2005. 